\title{
A questionnaire on satisfaction of family members regarding interdisciplinary family meetings in the intensive care unit
}

\author{
Christie M. Lee, MSc, MD, FRCPC (10) Marnie Jakab, BSc • \\ Brittany Marinelli, BSc · Alan Kraguljac, BSc, MSc • Christina Stevenson, BSc, MSc • \\ Andrea Moore, BSW, MSW, RSW • Nola Crewe, BA, MA, JD, MD • \\ Sangeeta Mehta, MD, FRCPC
}

Received: 6 February 2018/Revised: 3 February 2019/Accepted: 11 February 2019/Published online: 4 March 2019

(c) Canadian Anesthesiologists' Society 2019

\section{To the Editor,}

Family meetings are an integral component of patient care in the intensive care unit (ICU). These are formal meetings held between the patient's family or caregiver(s) and the inter-professional team. Often, critically ill patients cannot communicate directly with physicians; therefore, families depend on meetings to obtain information and advocate on behalf of patients to help guide care. ${ }^{1}$ The quality of communication between the ICU team and family can vary, with a survey of ICU directors citing family-related issues, such as patient inability to participate in discussions and suboptimal physician-family communication in end-of-life issues, as the largest barrier to improving ICU care. ${ }^{2}$ Family members value strong communication skills as much as physicians' clinical skills. ${ }^{3-5}$ Communication between the ICU team and families is a priority in improving overall ICU care. Most

C. M. Lee, MSc, MD, FRCPC ( $₫) \cdot$ S. Mehta, MD, FRCPC Department of Medicine, Mount Sinai Hospital, Toronto, Canada

e-mail: christie.lee@ sinaihealthsystem.ca

Interdepartmental Division of Critical Care Medicine, University of Toronto, Toronto, Canada

M. Jakab, BSc · B. Marinelli, BSc - A. Kraguljac, BSc, MSc. C. Stevenson, BSc, MSc

Department of Medicine, Mount Sinai Hospital, Toronto, Canada

A. Moore, BSW, MSW, RSW

Department of Social Work, Mount Sinai Hospital, Toronto, Canada

N. Crewe, BA, MA, JD, MD

Department of Chaplaincy, Mount Sinai Hospital, Toronto, ON, Canada research surrounding family meetings has involved audiotaped physician-family interactions, staff surveys, or development of mnemonics to aid clinicians facilitating a family meeting. Although family meetings have been linked to increased family satisfaction, literature is inconclusive on what elements make a family meeting effective from the perspective of families. We conducted a single-centre survey of 100 family meetings in the ICU to understand the perceptions of patient's families and caregivers with respect to the ICU family meeting and identify aspects of family meetings that correspond with family member satisfaction. This study was approved by the Mount Sinai Hospital Research Ethics Board on 20 August 2015. We identified five main domains of interest pertaining to the ICU family meeting: 1) trust, 2) comfort, 3) understanding, 4) decision-making, and 5) satisfaction. Questions focused on communication between the physicians and family members, understanding of terminology used during meetings, the sense of trust between physician and family members, and comfort provided in the meetings as perceived by respondents. The questionnaire also explored models of decisionmaking, type and timing of meetings, and included space for respondents to provide textual comments on their overall satisfaction and impressions of the family meeting.

Overall, 154 family members or caregivers participated in 100 family meetings in the ICU between September 2013 and June 2014. Of those surveyed, 94.6\% were satisfied with the family meetings. Comfort and acknowledgement of caregivers' experience improved communication as well as trust in the medical team. Families tend to prefer shared decision-making models and, if given a choice, prefer meetings that take place early within an ICU admission (between 24 and $48 \mathrm{hr}$ ). Please refer to the Table for results. A limitation of our study is 
Table Family members' perception regarding family meetings in the intensive care unit

\begin{tabular}{lrr}
\hline & $\begin{array}{l}\text { Yes (always, often) } \\
n / \text { total responses (\%) }\end{array}$ & $\begin{array}{l}\text { No (sometimes, no) \% } \\
n / \text { total responses (\%) }\end{array}$ \\
\hline Trust & $148 / 150(99)$ & $2 / 150(1)$ \\
Comfort (with team and in meeting to ask questions) & $130 / 145(90)$ & $15 / 145(10)$ \\
Understanding & $134 / 150(89)$ & $16 / 150(11)$ \\
Decision-making (shared) & $130 / 150(87)$ & $20 / 150(13)$ \\
Satisfaction & $145 / 154(94.6)$ & $9 / 154(5.4)$ \\
\hline
\end{tabular}

that we did not include patient or family member perspectives in the design of our questionnaire. Our questionnaire was also not validated, and our findings may not be generalizable to other centres. Despite the limitations, our study revealed that family members taking part in family meetings conducted in a single, academic ICU experienced more comfort/trust towards the ICU team, which led to more satisfaction with their family meetings. Family members prefer a shared decision-making model regardless of family meeting type. Further qualitative and quantitative research into this area, including follow-up with family members may provide more information regarding the conduct of effective and patient-centred family meetings.

Conflicts of interest None declared.

Editorial responsibility: This submission was handled by Dr. Gregory L. Bryson, Deputy Editor-in-Chief, Canadian Journal of Anesthesia.

Funding None.

\section{References}

1. Luce JM, Prendergast TJ. The changing nature of death in the ICU. In: Curtis JR, Rubenfeld GD, editors. Managing Death in the Intensive Care Unit - The Transition from Cure to Comfort. Oxford, UK: Oxford University Press, Inc.; 2001. p. 19-29.

2. Nelson JE, Angus DC, Weissfeld LA, et al. End-of-life care for the critically ill: a national intensive care unit survey. Crit Care Med 2006; 34: 2547-53.

3. Johnson D, Wilson M, Cavanaugh B, Bryden C, Gudmundson D, Moodley $O$. Measuring the ability to meet family needs in an intensive care unit. Crit Care Med 1998; 26: 266-71.

4. Hickey $M$. What are the needs of families of critically ill patients? A review of the literature since 1976. Heart Lung 1990; 19: 401-15.

5. Molter NC. Needs of relatives of critically ill patients: a descriptive study. Heart Lung 1979; 8: 332-9.

Publisher's Note Springer Nature remains neutral with regard to jurisdictional claims in published maps and institutional affiliations. 